\title{
Integrating information about location and value of resources by white-faced saki monkeys (Pithecia pithecia)
}

\author{
Elena Cunningham • Charles Janson
}

Received: 2 June 2005 / Revised: 5 January 2007 / Accepted: 21 January 2007 / Published online: 23 March 2007

(C) Springer-Verlag 2007

\begin{abstract}
Most studies of spatial memory in primates focus on species that inhabit large home ranges and have dispersed, patchy resources. Researchers assume that primates use memory to minimize distances traveled between resources. We investigated the use of spatial memory in a group of six white-faced sakis (Pithecia pithecia) on 12.8-ha Round Island, Guri Lake, Venezuela during a period of fruit abundance. The sakis' movements were analyzed with logistic regressions, a predictive computer model and a computer model that simulates movements. We considered all the resources available to the sakis and compared observed distances to predicted distances from a computer model for foragers who know nothing about the location of resources. Surprisingly, the observed distances were four times greater than the predicted distances, suggesting that the sakis passed by a majority of the available fruit trees without feeding. The odds of visiting a food tree, however, were significantly increased if the tree had been visited in the previous 3 days and had more than 100 fruit. The sakis' preferred resources were highly productive fruit trees, Capparis trees, and trees with water holes. They traveled efficiently to these sites. The sakis choice of feeding sites
\end{abstract}

This contribution is part of the Special Issue "A Socioecological Perspective on Primate Cognition" (Cunningham and Janson 2007).

E. Cunningham $(\square)$

Department of Basic Sciences and Craniofacial Biology, New York University College of Dentistry,

345 East 24th Street, New York, NY 10010, USA

e-mail: ec46@nyu.edu

\section{Janson}

Department of Ecology and Evolution, State University of New York at Stony Brook, Stony Brook, NY 11794, USA e-mail: janson@life.bio.sunysb.edu indicate that they combined knowledge acquired by repeatedly traveling through their home range with 'what' and 'where' information gained from individual visits to resources. Although the sakis' foraging choices increased the distance they traveled overall, choosing more valued sites allowed the group to minimize intragroup feeding competition, maintain intergroup dominance over important resources, and monitor the state of resources throughout their home range. The sakis' foraging decisions appear to have used spatial memory, elements of episodic-like memory and social and nutritional considerations.

Keywords Saki monkeys · Foraging · Spatial memory · Episodic memory

\section{Introduction}

The natural foraging behavior of animals provides multiple avenues for the study of their cognitive abilities. A primate looking for food may integrate spatial knowledge gained from repeatedly traveling through the home range with information, acquired during a recent feeding bout, on the number and maturity of fruit in a tree. The primate might also consider the behavior of members of his group, as well as the behavior of competitors outside the group and predators. Alternatively, a group of primates might just travel along a habitual trail (Di Fiore and Suarez 2007), feeding on whatever resources happen to be available and encountering competitors and predators by chance. It is impossible to rule out either of these possibilities a priori; perhaps either one could be true, depending on the species and ecological conditions. 
The ability to remember the location of resources could allow many primates to minimize the distances they travel between resources. Theoretically, primates that live in large home ranges and feed on highly dispersed and patchy foods can benefit the most from spatial memory and associated reduced travel costs (Milton 1981, 1988). For this reason, most observational and experimental field studies of spatial memory (e.g. Boesch and Boesch 1984; Garber 1988, 1989; Garber and Dolins 1996; Garber and Hannon 1993; Garber and Paciulli 1997; Janson 1996, 1998, 2007; Menzel 1991; Noser and Byrne 2007; Pochron 2001; Robinson 1986; Sigg and Stolba 1981; Valero and Byrne 2007) and experimental captive studies (e.g. Gallistel and Cramer 1996; MacDonald and Wilkie 1990; Menzel 1973; Menzel 1999; Tinklepaugh 1932) have focused on primates which, in nature, inhabit large home ranges with widely dispersed resources.

Although many fruit-eating primates use widely-dispersed resources, most species at least seasonally experience high densities of food patches (e.g. Terborgh 1983), and the density of food patches for leaf-eating primates is often reported to be high (e.g. Hladik 1977; Milton 1981). It is less obvious whether in situations of high food-patch density, reliance on spatial memory is necessary (Janson 1996). Even when food patches are common, primates might rely on spatial memory to travel to highly productive or preferred resources, rejecting less productive but closer resources (Garber 1989; Janson 1998, 2007). Conversely, certain trees might be avoided because they are distasteful (e.g. Glander 1978) or present a high predation risk (e.g. Cowlishaw 1997).

Given the rapidly changing state of fruit trees, frugivorous primates could benefit from remembering not only the locations of fruit trees, but also information from specific visits to fruit trees. Episodic memory refers to the ability to recollect the individual events of one's life. The definition of episodic memory includes conscious awareness of past events (Tulving 1972, 2002), making it very difficult to study in animals. Clayton et al. (2001, 2003a) suggest referring to memories of specific events in animals as episodic-like memories. They define episodic-like memories as long-term representations, formed in a single exposure and retaining 'where' 'what' and 'when' characteristics of an event. Episodic, or episodic-like, memory can be contrasted with semantic memory, in which a representation is constructed over multiple exposures to information and can be divorced from the spatial and temporal context in which it was acquired (Tulving 1972). Knowing the locations of five fruit markets in your area is an example of semantic memory; remembering buying a box of delicious raspberries in a particular store yesterday is an example of episodic memory.

Experimental studies have demonstrated that scrub blue jays are capable of episodic-like memory (Clayton et al. 2001, 2003b) and primates are capable of remembering 'what' and 'where' characteristics of events (see Schwartz and Evans 2001 for a review) and 'what' and 'who' characteristics (Schwartz et al. 2002). Clayton et al. (2003a) suggest considering the foraging behavior of frugivorous primates to learn more about episodiclike memory. As highly frugivorous primates, Pithecia, would benefit from the ability to integrate 'what', 'where' and 'when' information.

The Pithecia study group, examined here, inhabited a small home range and traveled short distances (averaging about $60 \mathrm{~m}$ ) between feeding and drinking bouts, most of which were brief and seemed relatively insignificant (Cunningham and Janson 2006). Several times a day, however, they had longer feeding bouts; usually in large Licania discolor (Chrysobalanaceae) trees or (less frequently) Capparis mисо (Capparidaceae) trees. The data we report here was collected at a time when fruiting Licania trees were abundant and the sakis would have had few problems locating nearby Licania trees without relying on spatial memory. We used four predictions to test the hypothesis that sakis use memory to travel to select resources.

The first prediction is that the sakis traveled to the nearest resources. If sakis rely on spatial memory, theoretically, they should minimize travel costs and travel to the nearest food sources. This prediction was tested using Janson's geometric model (1998) which predicts the distances at which the animals might detect resources without relying on spatial memory. If the sakis used spatial memory, they would be expected to beat the model by traveling shorter distances between resources.

The sakis might, however, choose to go to more distant and productive sites. Therefore, our second prediction is that when the availability of resources does not determine the sakis' route, the direction of travel is explained by more productive sites. We assume that sakis learn about the productivity of trees by visiting them. Therefore, our third prediction is that the sakis return to previously visited sights. Logistic regressions were used to predict the probability of a site being visited based on its distance, productivity, and whether or not the sakis had recently visited it. Nearer sites have a greater likelihood of being visited by chance and the sakis might pass by less productive sights until finding more productive ones. Therefore a significant increase in the probability of visiting sites based on distance and productivity does not, on its own, offer strong support 
for the memory hypothesis. A significant increase in the probability of returning to a previously visited site, with distance and productivity controlled for, however, indicates that the sakis were not wandering through the forest until coming upon the same productive resources by chance, but that they remembered the sites where they had recently fed and returned to them.

If the sakis' foraging route is determined by a few select sites, and other feeding sites are visited along the way, then the sakis should travel efficiently to the preferred sites. Therefore, our fourth prediction is that the sakis should travel more directly to preferred sites than expected by chance.

\section{Methods}

The study took place on Round Island, a 12.8-ha island in Guri Lake, Venezuela $(7.45 \mathrm{~N}, 62.52 \mathrm{~W})$ from January to June, 1996. The area has been described in Kinzey et al. (1988), and the site has been fully described in Cunningham (2003). The study group consisted of two adult Pithecia males, two adult females, one subadult female and one juvenile male. The members of the group were individually recognizable and well habituated. A second group of Pithecia living at the site consisted of one adult male and one adult female. Fourteen agonistic interactions between the two groups were observed.

Data was collected in two observation periods between March 10th and March 29th (P1) and between April 6th and April 26th (P2). Fruit accounted for 86\% of the sakis' feeding time in P1 and 79\% in P2. The overwhelming majority of the sakis' fruit-feeding time (87$88 \%$ ) was spent on the seeds of Licania discolor. Licania is a large tree and can have crops of 1,000 or more fruit. Each fruit contains only one seed and each seed weighs approximately $0.63 \mathrm{~g}(n=3)$. The number of Licania trees with more than 100 fruit fell from 27 to 17 between $\mathrm{P} 1$ and $\mathrm{P} 2$. Consequently, there was a drop of over $25 \%$ in the amount of time the sakis spent eating fruit. Capparis muco (Capparidaceae) was the species with the second highest number of feeding minutes in both periods. Sakis eat the mesocarp of Capparis. A small Capparis weighed $61.3 \mathrm{~g}$. Water in tree holes was an important resource for the sakis, especially in April when there was almost no rain. (See Cunningham 2003; Cunningham and Janson 2006 for detailed discussion of resource availability and the study group's socioecology.)

Cunningham and her assistant spent the first 5 days of each observation period collecting data on resource availability. They visually inspected (a) the plants that the Pithecia had been observed eating during previous studies (number of plants $=1,141)$ (Kinzey and Norconk 1993; Norconk 1996) or during the present study, and (b) plants that belong to species which are part of the sakis' diet, even if the study group of sakis had never been observed feeding at those individual plants. Plants were scored for the number of fruit, young leaves, and flowers present. Phenological data was also collected throughout the behavioral observation periods. Each observation period had its own resource database which was updated daily to reflect changes in resource availability. Terms concerning resources are defined in Table 1.

Two types of behavioral data were collected: focalanimal follows and group scans. During the focal animal follows, location and activity were noted every $5 \mathrm{~min}$ and all feeding and drinking bouts and their locations were recorded. The productivity of feeding trees was scored at the beginning and end of feeding bouts. Focal animal data was used for most analyses of feeding and ranging behavior. Each time an individual was selected as a focal animal, it was observed for four or five consecutive days. No individual served as a focal animal more than once during an observation period. Focal animal data is generally representative of group behavior because the group traveled as a cohesive unit. The group spread perpendicular to the groups' direction of movement was approximately $20 \mathrm{~m}$ (P1: $\mathrm{M}=21.1, \mathrm{SD}=14.6$; $\mathrm{P} 2: \mathrm{M}=17.9, \mathrm{SD}=15.4)$. Every $30 \mathrm{~min}$, an observer recorded the location, identity, activity, and time of sighting of the individuals in the study group.

The trail system of the island, the daily paths of the focal animals, the locations of the focal animals' feeding bouts, and the locations of sakis that were recorded during group scans were plotted on Tracker, a public-domain software package created by Charles Janson and Patrick Lee in 1995. Tracker recognizes map and trajectory (movements of an individual or group taken within a single day) databases. Five days (Sample Periods) were selected from each observation period for additional analysis. Days 4-8, the first 5 days in which "preferred" resources (defined in Table 1) were definable were chosen. Because Tracker has limited imaging capacities, Figs. 1 and 2 were created using Excel 2003 and Adobe Photoshop 7.0 (2002), based on coordinates from Tracker and scanned images from Tracker.

We tested the hypothesis that sakis know where their resources are located with the help of two computer models created by Charles Janson. Janson adapted the models used in the present study from models he uses in ongoing research with capuchin monkeys into movement rules in Iguazu National Park (Janson 1996, 1998; Janson and Di Bitetti 1997). 
Table 1 Definition of terms describing resources

\begin{tabular}{ll}
\hline Term & Definition \\
\hline Resource & 1. Any numbered tree that the sakis visited during the observation periods \\
& $\begin{array}{l}\text { 2. All numbered trees with fruit (whether or not they were visited) from "top" plant species. The sakis } \\
\text { spent more time eating "top" species than other species and there was a sharp reduction between the } \\
\text { amount of time sakis spent consuming top species and all others }\end{array}$ \\
& $\begin{array}{l}\text { 3. Trees with water holes } \\
\text { a }\end{array}$ \\
& $>100$ fruit \\
Less productive & $>100$ fruit \\
More productive & $101-350$ fruit \\
Preferred Licania & 351-750 fruit \\
Low productivity & $751-1,000$ fruit \\
Moderate productivity & $>1,000$ fruit \\
High productivity & Period One: Preferred Licania with high or very high productivity \\
Very high productivity & Period Two: Preferred Licania with moderate or high productivity \\
Highly preferred Licania & 1. >100 fruit and focal animal fed in tree during previous 3 days \\
Preferred resource & 2. Any Capparis tree that was visited, whether the sakis actually ate the fruit or checked the fruit's stage \\
& of ripeness (by visually inspecting, holding or putting their noses close to the fruit)
\end{tabular}

${ }^{a}$ Not considered as resources for logistic regressions because productivity scores could not be assigned

b During Period Two, no Licania trees had very high productivity scores. Therefore the sakis visited trees with moderate productivity more often

Fig. 1 Shown here is the focal animal's $(F A)$ daily path from the first two sample days and the distribution of productive Licania trees at that time. Continuous line outermost trail on island; arrows: direction of travel; circle outlines FA's feeding bouts, the size of the circle reflects length of feeding bout; triangles Licania trees with $\leq 100$ fruit; solid stars Licania trees with $>100$ fruit; $C$ Capparis tree; $W$ tree with water hole

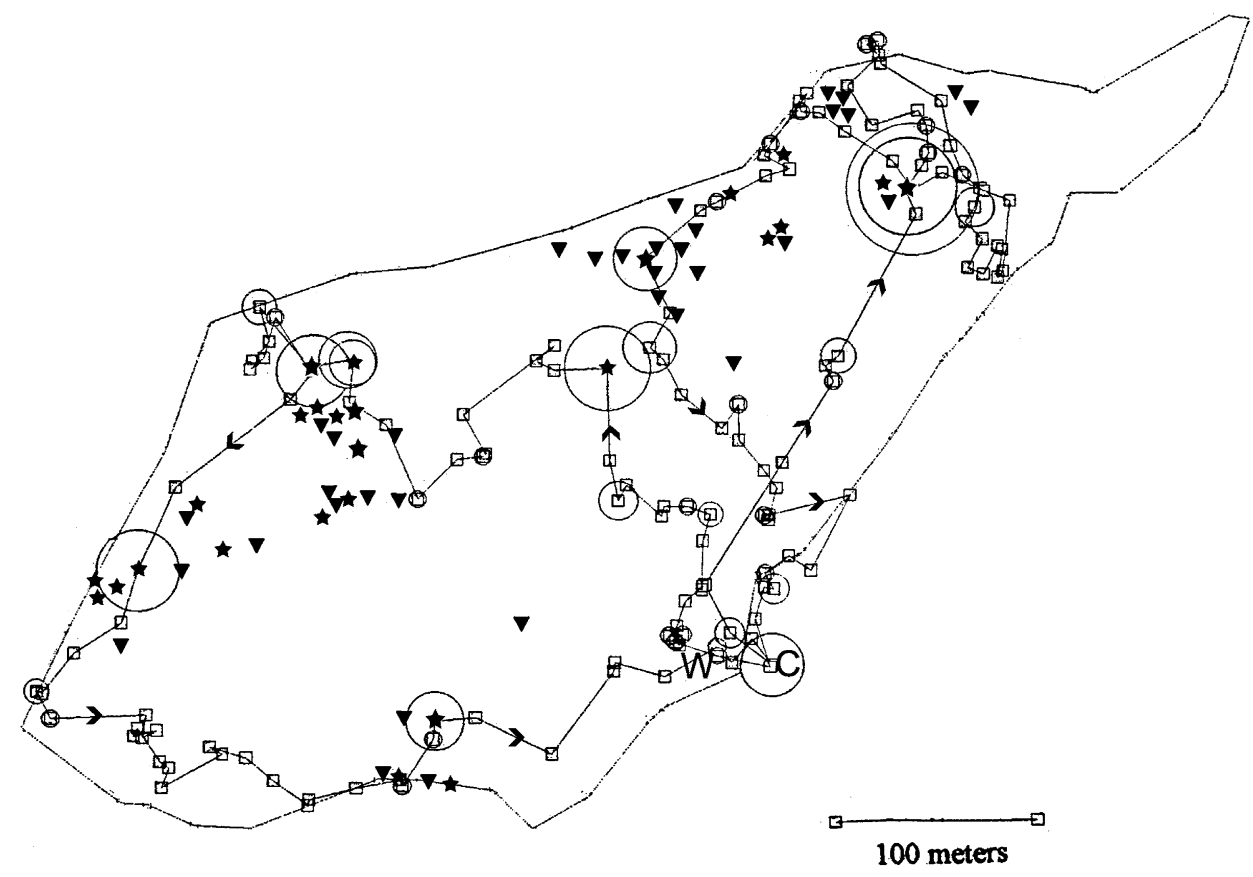

The geometric model

The study group's actual rate of encounters with resources and the distances the study group traveled to resources is compared with the random probabilities and distances predicted by the geometric model. The model assumes the following:
1. The group travels in a straight line away from a given site until it encounters the next 'resource' (See Table 1 for definition).

2. The group has a detection field within which it always detects a resource and beyond which it never does. Every resource within the detection field has an equal probability of being the next one 
Fig. 2 Final $100 \mathrm{~m}$ of some of the routes that the focal animals took to the four most frequently visited trees. Trees are represented by solid circles

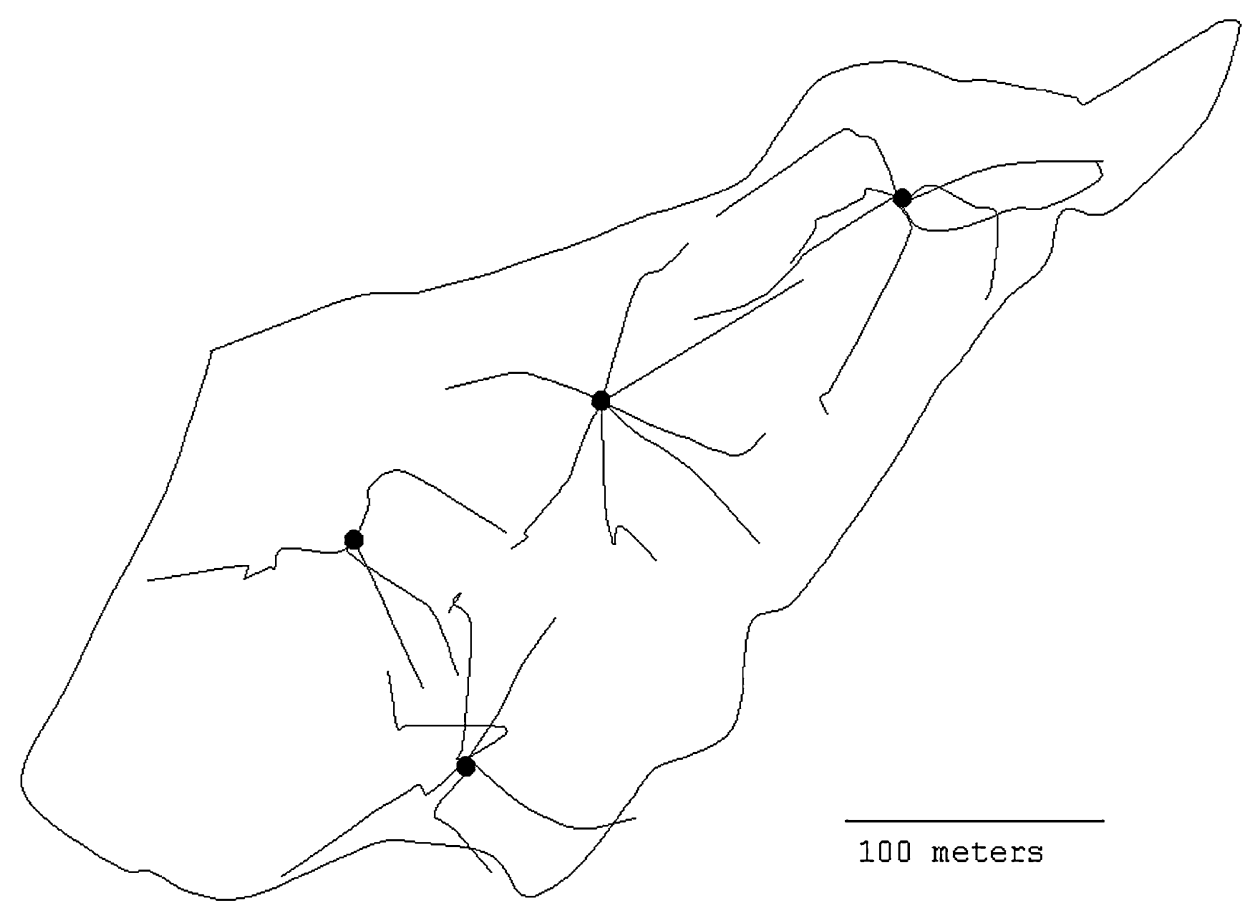

visited. In different runs of the model, the detection field can take on particular values between 10 and $80 \mathrm{~m}$. The study group's detection field was estimated as $60 \mathrm{~m}$ [the average group spread (approx. $20 \mathrm{~m}$ ) plus $20 \mathrm{~m}$ at each end of the spread]. This is a reasonable detection field for the study site. However, observed patterns of movement from the 'sample periods' were also tested against smaller and larger detection fields. Thirty meter was chosen as the smallest possible detection field (average group spread plus $5 \mathrm{~m}$ of visibility at each end of the spread). Eighty meter (average group spread plus $30 \mathrm{~m}$ of visibility at both ends of the spread) was chosen because Janson and DiBetti (1997) experimentally determined a mean detection field of $82 \mathrm{~m}$ for capuchins at Iguazu National Park and it was the largest detection field available.

3 . The direction of departure from a given site is chosen completely at random, independent even of the direction of the arrival at the site. Directions that do not lead to a resource are discarded.

Given these assumptions, the model calculates the probability that any resource will be the first one detected by a foraging group. See Janson (1998) for additional description of the model.

\section{Step model}

The model used for the present study generates expected probabilities for observed directness ratios for distances traveled to preferred resources assuming no knowledge of the resources. An observed directness ratio is the straight-line distance to a site divided by the cumulative distance of observed 'steps' to the site. A step is the distance from a start location to a (preferred or non-preferred) feeding or drinking site. The mean number of steps the sakis took to reach preferred resources was five. The model calculates expected directness ratios for 'target' distances. Target distances ranged from $50 \mathrm{~m}$ to the largest distance traveled to a preferred resource during an observation period. A focal animal is assumed to move from a starting location (generally the site of the previous feeding or drinking bout, but also sleeping trees) for a step. Step lengths and direction are randomly chosen from frequency distributions of distances and turning angles between start locations and the next feeding or drinking bout site; the frequency distributions used in this study were based on the observed movements of the study group. The distribution of step lengths was calculated in 5-m increments and the distribution of turning angles was calculated in $5^{\circ}$ increments. Every resource site that was visited during the 'sample' period was used to generate the observed frequency distributions.

Steps are randomly chosen until a distance within $10 \%$ of the target distance (the target range) is reached. Steps that make the cumulative distance traveled greater than that of the target range are discarded. Once the target range is reached, the model calculates the straight-line distance between the start and end 
points. The directness ratios generated by the model are the straight-line distance divided by the cumulative distance of step lengths. The program is repeated 200 times for every target distance. Each of the sets of 200 directness ratios is ranked from highest to lowest and the ranked ratios are labeled from 1 to 200.

Observed directness ratios are computed for distances between start locations and preferred sites, referred to here as a segment. Observed directness ratios are matched with the nearest expected directness ratio generated by the model for a 'random' route of equivalent total length. The rank number of that directness ratio, plus 1 , divided by 200 is the expected probability that simulated routes would generate directness ratios larger than those observed for a daily path segment ending in a given preferred site. Each such non-overlapping segment generated a distinct and independent directness ratio and associated probability value. Additional details of methods can be found in Cunningham (2003); see also Pochron (2001) for an application of this model.

\section{Results}

The study group's daily foraging pattern consisted of frequent short feeding bouts and a few long feeding bouts. The sakis traveled an average of $1,772 \mathrm{~m}$ per day. They averaged 25 feeding and drinking bouts per day. The average straight-line distance from starting locations to feeding and drinking bouts was $57 \mathrm{~m}$ during P1 and $63 \mathrm{~m}$ during P2 (Cunningham and Janson 2006). Figure 1 shows two representative day paths, locations of the focal animal's feeding and drinking bouts and the distribution of Licania trees. Over the course of study, the sakis visited Licania trees in every part of the island that the trees were located. There were no obstacles preventing sakis from visiting nearer Licania trees. Of the 27 trees that had $>100$ fruit, all but one was visited by the focal animals (Cunningham 2003). The sakis varied the paths by which they approached commonly used feeding trees (Fig. 2).

Four predictions were used to test the hypothesis that the study group used memory to travel efficiently to resource sites.

Prediction 1 The focal animals travel to the nearest resource more than predicted by the geometric model. The geometric model predicts the distances between successive resources encountered by the sakis without relying on spatial memory. The study group traveled much further than predicted by the geometric model. The focal animals selected trees that were, on average, about four times as far as the expected distance to a resource if the sakis chose a direction of travel randomly with a $60 \mathrm{~m}$ detection width (P1: $n=77-91$, M: Obs. $=80.8$, Exp. $=21.1$ SD: Obs. $=70.7$, Exp. $=20.9$; P2: $n=111-163, \quad$ M: Obs. $=80.1$, Exp. $=20.7$ SD: Obs. $=77.2$, Exp. 12.0). In most cases, the probability that the observed target site would be the first resource found was zero (zero probabilities: $\mathrm{P} 1=65 \%, \mathrm{P} 2=$ $67 \%$ ). A zero probability means that, given the assumptions of the model, the sakis would have to pass by a resource they should have detected to reach the resource they actually selected. The only plausible explanation of these results is that the sakis were extremely selective about the resources they ate.

Expected distances were not substantially different with larger or smaller detection widths. Detection ranges of 30, 60 and $80 \mathrm{~m}$ from the first 5-day sample period were examined and yielded expected movements between sites of, respectively, $26.6 \mathrm{~m}$ (SD = $32.8), 23.0 \mathrm{~m}(\mathrm{SD}=19.9)$, and $25.5 \mathrm{~m}(\mathrm{SD}=14.1)$. It may seem odd that the expected distances moved did not decline with increasing modeled detection distances (cf. Janson 1998). The resolution of this puzzle is that the density of all potential trees was so high that even at the shortest modeled detection field, there was a high probability that a food tree would occur within sight of the previous one. Thus, the expected distances between resources in the model largely reflected the mean distances between actual resources.

Prediction 2 In cases where the availability of resources does not explain the focal animal's route, the direction is determined by distant, more productive feeding trees.

Prediction 3 Sakis return to previously visited sites. The second and third predictions were tested with logistic regressions. In the first test, each move by the focal animal from one resource to another was considered one choice among all the resources (See Table 1 for definition). The number of potential resources varied daily, ranging from 77 to 153 . Table 2 provides information on resources and saki visits to resource sites. The chosen site was given an outcome of 1 , the "rejected" sites an outcome of 0 . Logistic regression was used to predict the probability of 1 versus 0 outcome for a potential site given three independent predictor variables: the straight-line distance from the starting site to each potential target, whether the target was less productive $(\leq 100$ food items) or more productive ( $>100$ food items), and whether or not the target site had been visited in the previous 3 days. 
Table 2 Counts and percentages of visited and not visited trees and shrubs grouped by productivity

\begin{tabular}{|c|c|c|c|c|c|}
\hline & \multicolumn{4}{|c|}{ Productivity } & \multirow[t]{3}{*}{ Total } \\
\hline & \multicolumn{2}{|l|}{ Less } & \multicolumn{2}{|l|}{ More } & \\
\hline & $1-10$ & $11-100$ & $101-1,000$ & $>1,000$ & \\
\hline \multicolumn{6}{|l|}{ (a) First period ${ }^{a}$} \\
\hline \multicolumn{6}{|l|}{ Not visited } \\
\hline Count & 170 & 588 & 349 & 68 & 1,175 \\
\hline$\%$ of not visited & 14.5 & 50.0 & 29.7 & 5.8 & 100.0 \\
\hline $\begin{array}{l}\% \text { with given } \\
\text { productivity score }\end{array}$ & 96.6 & 93.8 & 84.5 & 81.9 & 90.5 \\
\hline \multicolumn{6}{|l|}{ Visited } \\
\hline Count & 6 & 39 & 64 & 15 & 124 \\
\hline$\%$ of visited & 4.8 & 31.5 & 51.6 & 12.1 & 100.0 \\
\hline $\begin{array}{l}\% \text { with given } \\
\text { productivity score }\end{array}$ & 3.4 & 6.2 & 15.5 & 18.1 & 9.5 \\
\hline \multicolumn{6}{|l|}{ Total } \\
\hline Count & 176 & 627 & 413 & 83 & 1,299 \\
\hline$\%$ of total & 13.5 & 48.3 & 31.8 & 6.4 & 100.0 \\
\hline \multicolumn{6}{|l|}{ (b) Second period ${ }^{\mathrm{b}}$} \\
\hline Count & 543 & 816 & 423 & 0 & 1,782 \\
\hline$\%$ of not visited & 30.5 & 45.8 & 23.7 & 0 & 100.0 \\
\hline $\begin{array}{l}\% \text { with given } \\
\text { productivity score } \\
\text { Visited }\end{array}$ & 98.4 & 93.8 & 81.7 & 0 & 91.9 \\
\hline Count & 9 & 54 & 95 & 0 & 158 \\
\hline$\%$ of visited & 5.7 & 34.2 & 60.1 & 0 & 100.0 \\
\hline $\begin{array}{l}\% \text { with given } \\
\text { productivity score }\end{array}$ & 1.6 & 6.2 & 18.3 & 0 & 8.1 \\
\hline \multicolumn{6}{|l|}{ Total } \\
\hline Count & 552 & 870 & 518 & 0 & 1,940 \\
\hline$\%$ of Total & 28.5 & 44.8 & 26.7 & 0 & 100.0 \\
\hline
\end{tabular}

Plants are counted once on each day that they qualified as a "resource"

a 240 resources $(15.6 \%$ ) were not assigned productivity scores

b 331 resources $(14.6 \%$ ) were not assigned productivity scores

The results (Table 3 ) show that the sakis were more likely to visit closer, more productive resources, which they had visited in the previous 3 days. These results may seem to contradict the results of the geometric model which showed that the sakis traveled further than the expected distances. However, the geometric model included all potential resources as targets regardless of productivity or recent use. The logistic regression implies that among recently-used resources of similar productivity, the sakis indeed strongly preferred to use closer food trees. Figure 3 shows that although nearer resources were more likely to be visited than more distant ones, the probability of even the closest resources being visited was low. During both periods, the sakis preferred trees with high productivity scores that they had previously visited. Productivity was a stronger predictor in $\mathrm{P} 2$ when highly productive trees made up a smaller percentage of resources (Compare Table 2a
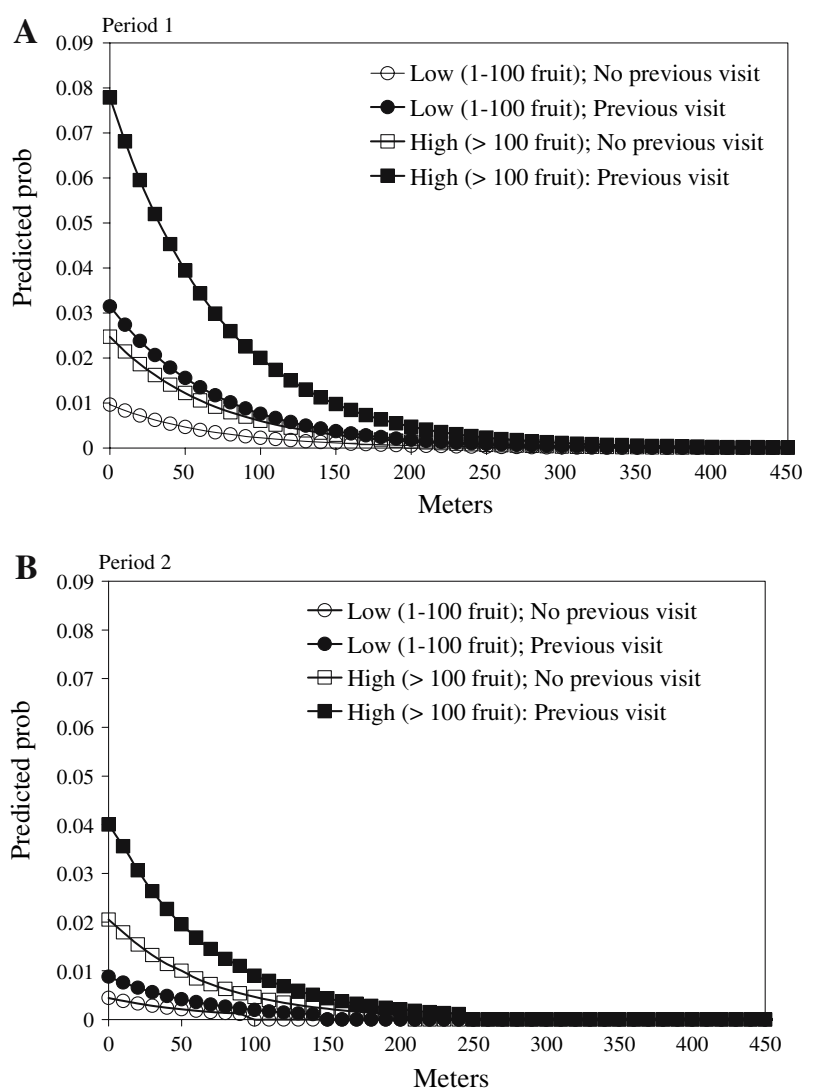

Fig. 3 Probability of visiting a resource site as a function of distance, productivity, and visit during previous 3 days. Probabilities are derived from results in Table 3. Prob Probability

and b). During P2, therefore, there was less likelihood of coming across highly productive trees by chance. Previous visit was a weaker predictor in $\mathrm{P} 2$. As the amount of fruit on trees decreased, even among trees with high scores (Compare Table $2 \mathrm{a}$ and $\mathrm{b}$ ), the value of return visits also decreased.

A second set of logistic regressions was conducted to control for differences in resource size and type. Although the same three predictor variables were used, only Licania trees were included in this subset of data. The significance levels in the two sets were not substantially different. To save space, we are not including tables with the results here (for tables see Cunningham 2003). The similarity in the results of these sets of logistic regressions occurred because Licania accounted for the overwhelming majority of feeding minutes.

To further investigate the effect of productivity on site choice, we conducted another set of logistic regressions, restricted to preferred Licania trees (those with more than 100 fruit that had been visited in the previous 3 days). This set of logistic regressions analyzed the probability of a site being visited as a function of its straight-line distance from a starting site and its 
Table 3 Results of logistic regressions using distance, productivity and visit during previous 3 days to predict the probability of a tree being visited

\begin{tabular}{|c|c|c|c|c|c|}
\hline Variable & $B$ & S.E. & $\chi^{2}$ & $d f$ & $P$ \\
\hline \multicolumn{6}{|c|}{ (a) First period ${ }^{\mathrm{a}}$} \\
\hline Distance & -0.0144 & 0.0014 & 106.4604 & 1 & $<0.0001$ \\
\hline Productivity & 0.9553 & 0.2145 & 19.8431 & 1 & $<0.0001$ \\
\hline Prev. visit & 1.2022 & 0.2007 & 35.8762 & 1 & $<0.0001$ \\
\hline Constant & -4.6284 & 0.3873 & 142.8034 & 1 & $<0.0001$ \\
\hline Model & & & 243.503 & 3 & $<0.0001$ \\
\hline \multicolumn{6}{|c|}{ (b) Second period ${ }^{\mathrm{b}}$} \\
\hline Distance & -0.0150 & 0.0013 & 140.4665 & 1 & $<0.0001$ \\
\hline Productivity & 1.5472 & 0.1913 & 65.4233 & 1 & $<0.0001$ \\
\hline Prev. visit & 0.6883 & 0.1842 & 13.9609 & 1 & $<0.001$ \\
\hline Constant & -5.4115 & 0.3291 & 270.4390 & 1 & $<0.0001$ \\
\hline Model & & & 332.598 & 3 & $<0.0001$ \\
\hline
\end{tabular}

Movement decisions to selected trees are predicted as a function of distance between starting and target trees, the productivity score of target tree, and whether or not the target tree had been visited during the previous 3 days. The dependent variable is the ln of $P /(1-P)$, where $P$ is the observed probability of visiting a selected tree

a Nagelkerke - $R^{2}=0.199$

b Nagelkerke $-R^{2}=0.205$

productivity score $($ Low $=101-350 ;$ Moderate $=351$ 750 , High $=751-1,000$, Very High $>1,000)$. Table 4 provides information on preferred Licania trees and saki visits to them. Although only preferred Licania trees were considered potential target sites in the third analysis, preferred resource sites (See Table 1 for definition) qualified as start locations. Trees with water holes and Capparis trees (whose large fruits ripened one at a time) were not included as potential target sites because it was not possible to assign meaningful productivity scores to these resources.

In P1, both distance and productivity were significant predictors (Table 5). In P2, when the productivity of trees began to drop (Table 4), it appears that the distance of a site became a more important predictor of visited sites, and productivity became less important. Table 4 shows that trees with High and Very High productivity scores were usually revisited. On two of the three occasions that a tree with a Very High score was not revisited, the sakis slept in the vicinity of the tree, without feeding in it that day, and fed on the fruit of the tree before leaving the area the following morning. The third occasion on which a tree with a Very High score was not revisited, and all occasions that a Highscoring tree was not revisited, were accounted for by a single tree, 10348. Tree 10348 was consistently underutilized. Perhaps there was a greater threat of predation associated with tree 10348 than other Licania

Table 4 Counts and percentages of preferred Licania trees that were revisited grouped by productivity score

\begin{tabular}{|c|c|c|c|c|c|}
\hline & \multicolumn{4}{|c|}{ Productivity score } & \multirow[t]{2}{*}{ Total } \\
\hline & Low (101-350) & Moderate (351-750) & High (751-1,000) & Very high $(>1,000)$ & \\
\hline \multicolumn{6}{|l|}{ (a) First period } \\
\hline \multicolumn{6}{|l|}{ Not visited } \\
\hline Count & 7 & 24 & 3 & 3 & 37 \\
\hline$\%$ of not visited & 18.9 & 64.9 & 8.1 & 8.1 & 100.0 \\
\hline$\%$ with given productivity score & 87.5 & 85.7 & 37.5 & 42.9 & 72.5 \\
\hline \multicolumn{6}{|l|}{ Visited } \\
\hline Count & 1 & 4 & 5 & 4 & 14 \\
\hline$\%$ of visited & 7.1 & 28.6 & 35.7 & 28.6 & 100.0 \\
\hline$\%$ with given productivity score & 12.5 & 14.3 & 62.5 & 51.7 & 27.5 \\
\hline \multicolumn{6}{|l|}{ Total } \\
\hline Count & 8 & 28 & 8 & 7 & 51 \\
\hline$\%$ of total & 15.7 & 54.9 & 15.7 & 13.7 & 100.0 \\
\hline \multicolumn{6}{|l|}{ (b) Second period } \\
\hline \multicolumn{6}{|l|}{ Not visited } \\
\hline Count & 30 & 12 & 2 & 0 & 44 \\
\hline$\%$ of not visited & 68.2 & 27.3 & 4.5 & 0 & 1 \\
\hline$\%$ with given productivity score & 85.7 & 66.7 & 28.6 & 0 & 73.3 \\
\hline \multicolumn{6}{|l|}{ Visited } \\
\hline Count & 5 & 6 & 5 & 0 & 16 \\
\hline$\%$ of visited & 31.3 & 37.5 & 31.3 & 0 & 100.0 \\
\hline$\%$ with given productivity score & 14.3 & 33.3 & 71.4 & 0 & 26.7 \\
\hline \multicolumn{6}{|l|}{ Total } \\
\hline Count & 35 & 18 & 7 & 0 & 60 \\
\hline$\%$ of total & 58.3 & 30 & 11.7 & 0 & 100.0 \\
\hline
\end{tabular}

Preferred Licania trees have been visited in the previous 3 days and $>100$ fruit. Each Licania tree is counted once on each day that it qualified as a "preferred resource" 
Table 5 Results of logistic regressions using distance and productivity to predict the probability of a preferred Licania tree being revisited

\begin{tabular}{|c|c|c|c|c|c|}
\hline Variable & $\beta$ & S.E. & $\chi^{2}$ & $d f$ & $P$ \\
\hline \multicolumn{6}{|c|}{ (a) First period ${ }^{a}$} \\
\hline Distance & -0.0085 & 0.0031 & 7.5377 & 1 & $<0.01$ \\
\hline Productivity & 1.0372 & 0.3297 & 9.8968 & 1 & $<0.01$ \\
\hline Constant & -3.3162 & 0.9564 & 12.0231 & 1 & $<0.001$ \\
\hline Model & & & 18.652 & 2 & $<0.001$ \\
\hline \multicolumn{6}{|c|}{ (b) Second period ${ }^{\mathrm{b}}$} \\
\hline Distance & -0.0113 & 0.0033 & 11.6571 & 1 & $<0.001$ \\
\hline Productivity & 0.6095 & 0.3476 & 3.0744 & 1 & 0.0795 \\
\hline Constant & -1.4546 & 0.8055 & 3.2609 & 1 & 0.0709 \\
\hline Model & & & 23.894 & 2 & $<0.0001$ \\
\hline
\end{tabular}

Movement decisions to selected trees are predicted as a function of distance between starting and target trees and the productivity score of target tree. Preferred Licania trees have been visited in the previous 3 days and $>100$ fruit. The dependent variable is the ln of $P /(1-P)$, where $P$ is the observed probability of visiting a selected tree

a Nagelkerke - $R^{2}=0.251$

b Nagelkerke $-R^{2}=0.256$

trees. It is high on the mountain peak that is the study site and it is the most exposed of the Licania trees.

If the sakis favored the Licania trees with the most fruit, they should travel to the nearest highly-preferred Licania tree. In P1, we considered Licania trees with a High (751-1,000 fruit) or Very High ( $>1,000$ fruit) score as highly preferred. In P2, we considered trees with a Moderate (351-750 fruit) or High (751-1,000 fruit) score as highly preferred (no trees had $>1,000$ fruit). The mean number of highly preferred Licania trees that the sakis had to choose from was 2.6 during P1 and 4.6 during the P2. We used simple geometry to calculate distances to each highly-preferred Licania tree from each start location. Once a resource was visited, it was removed from the set of highly preferred Licania for the remainder of that day.

In 13 out of 20 choices, sakis went to the nearest highly-preferred Licania. On two of the seven occasions that they selected a more distant tree, it had a higher productivity score than the closer tree. Two other occasions occurred on the same day: tree 11031 was nearer than both of the trees that were visited. Tree 11031 was downgraded to Low productivity 2 days later. It is likely that it also had less fruit than the tree that the sakis traveled to. Therefore, in 17 of the 20 choices, the sakis made economical travel decisions based on distance and productivity. In each of the three cases that they did not select the nearest or most productive tree, Tree 10348 was the nearest tree. In each of these cases the sakis selected Tree 11031, which on those days had more fruit than any other Licania tree which had not been visited yet.
Next we used the Step Model to test the efficiency of the sakis' routes to preferred resources.

Prediction 4 If knowledge of the location of select resources determines the focal animal's route, the probability of observed directness ratios should differ significantly from those expected by chance.

The step model was used to determine the probability of observed directness ratios (straight line distance/ cumulative distance of observed 'steps') to preferred resources (See Table 1 for definition). Directness ratios were calculated for preferred sites because $1 / 3$ of the Licania that sakis revisited in $\mathrm{P} 1$ and $\mathrm{P} 2$ qualified as preferred sites, but not as highly preferred sites (Table 4).

The sample periods were treated individually for this analysis. A separate frequency distribution of observed distances and turning angles was compiled for each period. Directness ratios and associated probabilities were analyzed only for resources more than $100 \mathrm{~m}$ from the observed start location because resources less than $100 \mathrm{~m}$ from start locations had high expected probabilities, even for directness ratios of 1 . Directness ratios of 1.0 mean that the focal animal did not stop to feed between resources.

Table 6 presents a list of observed distances, directness ratios and probabilities for preferred resources. The average distance between start locations and analyzed preferred resources was $242.7 \mathrm{~m}(\mathrm{SD}=104.3)$ in $\mathrm{P} 1$ and $246.1 \mathrm{~m}$ in $\mathrm{P} 2(\mathrm{SD}=139.7)$. The average directness ratio was 0.84 for $\mathrm{P} 1$ and 0.82 for $\mathrm{P} 2$.

The probabilities of the directness ratio for each observed move were independent of each other move, as they occurred in non-overlapping segments of the sakis daily travel path. Therefore, it was appropriate to use Fisher's method of combining probabilities across independent tests to test the general hypothesis that observed directness ratios were larger than expected by chance. Results from the Fisher technique of combining probabilities (Sokal and Rohlf 1995, pp. 794 797) were significant ( $\mathrm{P} 1: \chi^{2}=62.10, d f=30, P<0.001$; $\left.\mathrm{P} 2: \chi^{2}=70.83, d f=36, P<0.001\right)$.

\section{Discussion}

When fruiting Licania trees were abundant, the sakis traveled efficiently to the trees with the most fruit, often ignoring closer, but less productive trees. They also selected fruiting Capparis trees and trees with water holes as travel goals. Given the large distances (nearly $250 \mathrm{~m}$ ) between start locations and analyzed preferred resources, it is extremely unlikely that the 
Table 6 Travel to preferred resources: distances, directness ratios and probabilities

\begin{tabular}{|c|c|c|}
\hline Observed distance & Observed D.R. & Probability \\
\hline \multicolumn{3}{|l|}{ (a) First period ${ }^{a}$} \\
\hline 133 & 1.000 & 0.075 \\
\hline 307 & 0.542 & 0.530 \\
\hline 144 & 1.000 & 0.085 \\
\hline 267 & 0.939 & 0.080 \\
\hline 142 & 0.955 & 0.150 \\
\hline 230 & 0.929 & 0.050 \\
\hline 237 & 0.691 & 0.400 \\
\hline 384 & 0.790 & 0.105 \\
\hline 248 & 1.000 & 0.035 \\
\hline 118 & 1.000 & 0.090 \\
\hline 189 & 0.715 & 0.450 \\
\hline 412 & 0.738 & 0.180 \\
\hline 205 & 0.419 & 0.805 \\
\hline 176 & 1.000 & 0.025 \\
\hline 449 & 0.841 & 0.075 \\
\hline \multicolumn{3}{|l|}{ (b) Second period ${ }^{\mathrm{b}}$} \\
\hline 327 & 0.579 & 0.480 \\
\hline 170 & 0.955 & 0.100 \\
\hline 153 & 0.957 & 0.075 \\
\hline 108 & 0.987 & 0.170 \\
\hline 108 & 0.897 & 0.320 \\
\hline 103 & 0.976 & 0.225 \\
\hline 383 & 0.844 & 0.045 \\
\hline 194 & 0.903 & 0.105 \\
\hline 306 & 0.985 & 0.015 \\
\hline 150 & 0.582 & 0.625 \\
\hline 315 & 0.905 & 0.050 \\
\hline 150 & 0.995 & 0.075 \\
\hline 510 & 0.447 & 0.515 \\
\hline 252 & 0.691 & 0.345 \\
\hline 555 & 0.263 & 0.835 \\
\hline 106 & 1.000 & 0.150 \\
\hline 174 & 0.840 & 0.255 \\
\hline 365 & 0.968 & 0.010 \\
\hline
\end{tabular}

Only preferred resources in which the cumulative distance of steps was more than $100 \mathrm{~m}$ from the start trees were included. Preferred resources were defined as trees with high productivity scores ( $>100$ fruit) that had been visited in the previous 3 days, any Capparis muco tree and trees with water holes. Distance is the sum of steps in meters

$D R$ directness ratio

${ }^{a}$ Fisher method of combining probabilities: $\chi^{2}=62.09727$ $(d f=30, P<0.001)$

${ }^{\mathrm{b}}$ Fisher method of combining probabilities: $\chi^{2}=70.83474$ $(d f=36, P<0.001)$

sakis detected these resources or were guided by local cues such as bird song, the presence of other monkeys in fruit trees, or the odor of the resources (Licania is not a highly odiferous fruit). These results are consistent with the results of an experimental study of whitefaced sakis which showed that they can use spatial memory to find food, even when olfactory cues are controlled (Cunningham 2003). Sakis approached favorite feeding sites from multiple directions (Fig. 2) and visited virtually all highly productive Licania trees during the course the study (Cunningham 2003). If the sakis used habitual paths, as Milton (2000) suggests for howler monkeys and Di Fiore and Suarez (2007) suggest for spider and woolly monkeys, the network of paths was so extensive that the sakis had to use memory to know which paths led efficiently to resources. The results indicate that when resources were abundant, the sakis used spatial memory to travel to preferred resources.

\section{What and where}

The sakis were not simply relying on knowledge of Licania locations which they had accumulated over years of repeated exposure. The sakis were also making judgments of the relative value of Licania trees. Perhaps the sakis remembered relative quantities of food in various trees or the sakis remembered their feeding rates in different trees. As the most productive Licania trees became depleted, the sakis started visiting less productive trees more often. The sakis decisions were based on the current availability of fruit, suggesting that they relied not only on semantic memory, but also remembered "what" and "where" characteristics of individual feeding bouts for several days. It is less clear whether or not the sakis remembered 'when' a feeding bout occurred. Sakis often waited 3 days or longer before revisiting Licania trees (Cunnningham 2003). They might have been integrating information on the maturity of the Licania fruit and waiting longer to return to trees with less mature fruit. We do not have evidence, however, that they remembered the specific times of their visits. Therefore, the sakis behavior falls short of the criteria for episodic-like memory. Nonetheless, the most parsimonious explanation of the sakis' decisions is that they were based on specific memories of feeding bouts in particular trees, whether or not the sakis could relate those memories to specific times or simply remembered that the feeding bouts were recent. The alternative is that the sakis constantly revised semantic representations with transient information based on individual experiences, a scenario which seems less parsimonious. To maintain that all memories of events in one's own life must include information on "where", "what", and "when" characteristics, limits our ability to understand the evolution and development of personal memories.

\section{Why select distant resources}

Moderately productive Licania trees were plentiful and widely distributed (Fig. 2 and Table 4). Instead of 
traveling between the most highly productive Licania trees, the sakis could have visited one highly productive Licania tree and increased visits to neighboring, less productive trees. Traveling to more distant Licania trees increased the sakis' energy costs and exposure to predators. Potential saki predators in the area include jaguars (Panthera onca) and red-tailed boas (Boa constrictor). Although harpy eagles (Harpia harpyja) may be locally extinct, sakis frequently alarm call in response to other raptors and have remained motionless in the understory for an hour or longer when they have felt threatened (Gleason and Norconk 2002; Personal observation).

Although the sakis incurred costs and risks by traveling further for resources, they also benefited from this strategy. In a concurrent study, Harrison-Levine (1998) found that the study group's feeding party size was most strongly correlated with the productivity and crown size of feeding trees $\left(r^{2}=0.68, P<0.001, n=2099\right)$ and that aggression levels in the group were lowest in the most productive trees with the largest tree crowns [MannWhitney $U$ Test, $U=19099.5, z=-2.70, P<0.01$ (onetailed), $n=2099$ ]. Competition was low because it took the sakis fewer seconds to eat a Licania seed in more productive trees $[r=-0.397, P<0.001$ (one-tailed), $r_{\mathrm{s}}=-0.37, P<0.001$ (one-tailed) $n=93$ ] (Cunningham 2003) resulting in greater nutritional gain. Therefore, even though group size was highest in the most productive trees, sakis had the greatest feeding success and the lowest levels of aggression in these trees. The extra distance the sakis traveled to reach the most productive resources may have been a small price to pay as it allowed them to reap the benefits of group cohesion while minimizing its chief disadvantage-intragroup feeding competition.

Competition with another group of sakis for the most productive Licania trees may have also been a factor. Of 22 aggressive encounters with the second group of sakis, 20 began within $100 \mathrm{~m}$ of a preferred resource (Cunningham 2003). Frequent visits to the most productive and valued resources may have helped the group maintain dominance over those resources. In addition, by taking different routes to distant feeding trees, the sakis were able to monitor the phenological state of resources over a larger part of their home range. It seems that knowing the locations of fruiting trees can serve an important function for primates living in small home ranges with abundant and widely dispersed resources.

For primates living in large home ranges, travel to the "nearest neighbor" does not necessarily mean to the nearest food source either. Productivity is probably one of the most important variables in determining which resources primates select as destinations (Cunningham and Janson 2007; Garber 1989; Janson 1998, 2007; Janson and Byrne 2007). A scarce, essential resource such as water could also determine travel path (Sigg 1986). Sometimes, it might be hard to quantify or identify the characteristics of a resource that make it 'preferred'. In the present study, Capparis might have been preferred because it was sweeter than the seeds that made up the bulk of the sakis' diet (Norconk and Conklin-Brittain 2004). Likewise, Garber's (1988) study focuses on trap lining between Symphonia globulifera (Guttiferae) trees by tamarins, which eat the nectar of these trees. Symphonia accounted for only $22-31 \%$ of the tamarins' feeding time, yet it largely determined the group's travel route.

In some circumstances, primates may consider more that the location of feeding sites when making foraging decisions. Primates' travel decisions may also be based on value judgments of resource sites that take into consideration social as well as dietary needs and preferences.

Acknowledgments This research was funded by grants to Elena Cunningham from the CUNY Graduate School, L.S.B. Leakey Foundation, W.G. Kinzey Fund, and the Wenner-Gren Foundation. We are grateful to the administration of Edelca for allowing the primates of Guri Lake to be studied. We thank Marilyn Norconk for generously sharing unpublished data with us and for helping EC work at the study site. Amy Harrison-Levine assisted EC in the field. EC thanks her for her hard work, insights, and companionship. EC also thanks John Robinson, Eric Delson, and Sharon Himmanen for their comments. EC is extremely grateful to Karyl Swartz whose comments and support were essential.

\section{References}

Boesch C, Boesch H (1984) Mental map in wild chimpanzees: an analysis of hammer transports for nutcracking. Primates 25:160-170

Clayton NS, Bussey TJ, Dickinson A (2003a) Can animals recall the past and plan for the future? Nat Rev Neurosci 4:685-691

Clayton NS, Yu KS, Dickinson A (2001) Scrub jays (Aphelocoma coerulescens) form integrated memories of the multiple features of caching episodes. J Exp Psychol Anim Behav Process 27:17-29

Clayton NS, Yu KS, Dickinson A (2003b) Interacting cache memories: evidence for flexible memory use by western scrub-jays (Aphelocoma californica). J Exp Psychol Anim Behav Process 29:14-22

Cowlishaw G (1997) Trade-offs between foraging and predation risk determine habitat use in a desert baboon population. Anim Behav 53:667-686

Cunningham EP (2003) The use of memory in Pithecia pithecia's foraging strategy. PhD dissertation, Anthropology, City University of New York. Available from: University Microfilms, Ann Arbor, 64-03:973

Cunningham E, Janson C (2006) Pithecia pithecia's behavioral response to decreasing fruit abundance. Am J Primatol 68:491-407 
Cunningham E, Janson C (2007) A socioecological perspective on primate cognition, past and present. Anim Cogn. doi: 10.1007/s10071-007-0078-3

Di Fiore A, Suarez S (2007) Route-based travel and shared routes in sympatric spider and woolly monkeys: cognitive and evolutionary implications. Anim Cogn. doi:10.1007/s10071-0060067-y

Gallistel C, Cramer A (1996) Computations on metric maps in mammals: getting oriented and choosing a multi-destination route. J Exp Biol 199:211-217

Garber P (1988) Foraging decisions during nectar feeding by tamarin monkeys (Saguinus mystax and Saguinus fuscicollis, Callitrichidae, Primates) in Amazonian Peru. Biotropica 20:100-106

Garber P (1989) Role of spatial memory in primate foraging patterns: Saguinus mystax and Saguinus fuscicollis. Am J Primatol 19:203-216

Garber P, Dolins F (1996) Testing learning paradigms in the field: evidence for use of spatial and perceptual information and rule-based foraging in wild mustached tamarins. In: Norconk M, Rosenberger A, Garber P (eds) Adaptive radiations of neotropical primates. Plenum, New York pp 201-216

Garber P, Hannon B (1993) Modeling monkeys; a comparison of computer-generated and naturally occurring foraging patterns in two species of neotropical primates. Int $\mathbf{J}$ Primatol 14:827-852

Garber P, Paciulli L (1997) Experimental field study of spatial memory and learning in wild capuchin monkeys (Cebus capucinus). Folia Primatol 68:236-253

Glander K (1978) Howling monkey feeding behavior and plant secondary compounds: a study of strategies. In: Montgomery $\mathrm{G}$ (ed) The ecology of arboreal folivores. The symposia of the National Zoological Park, Smithsonian Institution, Washington DC, pp 561-574

Gleason T, Norconk M (2002) Predation risk and antipredator adaptations in white-faced sakis, Pithecia pithecia. In: Miller L (ed) Eat or be eaten: predator sensitive foraging among primates. Cambridge University Press, New York pp 211227

Harrison-Levine A (1998) Feeding party dynamics of white-faced sakis in Lago Guri, Venezuela. Unpublished Master of Arts thesis, Kent State University, Ohio

Hladik C (1977) A comparative study of the feeding strategies of two sympatric species of leaf monkeys: Presbytis senex and Presbytis entellus. In: Clutton-Brock T (ed) Primate ecology: studies of feeding and ranging behaviour in lemurs, monkeys, and apes. Academic, New York pp 323-353

Janson C (1996) Toward an experimental socioecology of primates. In: Norconk M, Rosenberger A, Garber P (eds) Adaptive radiations of neotropical primates. Plenum, New York pp 309-328

Janson C (1998) Experimental evidence for spatial memory in foraging wild capuchin monkeys. Cebus apella. Anim Behav 55:1229-1243

Janson C (2007) Experimental evidence for route integration and strategic planning in wild capuchin monkeys. Anim Cogn. doi:10.1007/s10071-007-0079-2

Janson C, Byrne R (2007) What wild primates know about resources-opening up the black box. Anim Cogn. doi:10.1007/ s10071-007-0080-9

Janson C, Di Bitetti M (1997) Experimental analysis of food detection in capuchin monkeys; effects of distance, travel speed, and resource size. Behav Ecol Sociobiol 41:17-24

Kinzey W, Norconk M, Alvarez-Cordero E (1988) Primate survey of eastern Bolivar, Venezuela. Primate Conserv 9:6670
Kinzey W, Norconk M (1993) Physical and Chemical Properties of fruit and seeds eaten by Pithecia and Chiropotes in Surinam and Venezuela. Int J Primatol 14:207-227

MacDonald S, Wilkie D (1990) Yellow-nosed monkeys (Cercopithecus ascanius whitesidei) spatial memory in a simulated foraging environment. J Comp Psychol 104:382-387

Menzel C (1991) Cognitive aspects of foraging in Japanese monkeys. Anim Behav 41:397-402

Menzel C (1999) Unprompted recall and reporting of hidden objects by a chimpanzee (Pan troglodytes) after extended delays. J Comp Psychol 113:426-434

Menzel E (1973) Chimpanzee spatial memory organization. Science 182:943-945

Milton K (1981) Distribution patterns of tropical plant foods as an evolutionary stimulus to primate mental development. Am Anth 83:534-548

Milton K (1988) Foraging behavior and the evolution of primate intelligence. In: Byrne R, Whiten A (eds) Machiavellian intelligence: social expertise and the evolution of intellect in monkeys, apes, and humans. Clarendon, Oxford, pp 285-305

Milton K (2000) Quo Vadis? Tactics of food search and group movement in primates and other animals. In: Boinski S, Garber P (eds) On the move: how and why animals travel in groups. The University of Chicago, Chicago, pp 375-417

Norconk M (1996) Seasonal variation in the diets of white-faced sakis (Pithecia pithecia and Chiropotes satanas) in Guri Lake, Venezuela. In: Norconk M, Rosenberger A, Garber P (eds) Adaptive radiations of neotropical primates. Plenum, New York pp 403-425

Norconk M, Conklin-Brittain NL (2004) Variation on frugivory: the diet of Venezuelan white-faced sakis. Int J Primatol 25:1-26

Noser R, Byrne R (2007) Mental maps in chacma baboons (Papio ursinus): using inter-group encounters as a natural experiment. Anim Cogn. doi:10.1007/s10071-006-0068-x

Pochron S (2001) Can concurrent speed and directness of travel indicate purposeful encounter in the yellow baboons (Papio hamadryas cynocephalus) of Ruaha National Park, Tanzania? Am J Primatol 22:773-785

Robinson J (1986) Seasonal variation in use of time and space by the wedge-capped capuchin monkey, Cebus nigrivittatus. Anim Behav 29:1036-1056

Sigg H (1986) Ranging patterns in hamadrayas baboons: evidence for a mental map. In: Else J, Lee P (eds) Primate ontogeny, cognition, and social behavior. Cambridge University, New York pp 87-91

Sigg H, Stolba A (1981) Home range and daily march in a hamadrayas baboon troop. Folia Primatol 36:40-75

Schwartz B, Colon I, Sanchez I, Rodriguez, Evans S (2002) Single-trial learning of 'what' and 'who' information in a gorilla (Gorilla gorilla gorilla): implications for episodic memory. Anim Cogn 5:85-90

Schwartz B, Evans S (2001) Episodic memory in primates. Am J Primatol 55:71-85

Sokal R, Rohlf F (1995) Biometry. WH Freeman, New York

Terborgh J (1983) Five new world primates. Princeton University, Princeton

Tinklepaugh O (1932) The multiple delayed reaction with chimpanzees and monkeys. J Comp Psychol 13:207-243

Tulving E (1972) Episodic and semantic memory. In: Tulving E, Donaldson W (eds) Organization of memory. Academic, San Diego, pp 381-403

Tulving E (2002) Episodic memory: from mind to brain. Annu Rev Psychol 53:1-25

Valero A, Byrne RW (2007) Spider monkey ranging patterns in Mexican subtropical forest: do travel routes reflect planning? Anim Cogn. doi:10.1007/s10071-006-0066-Z 